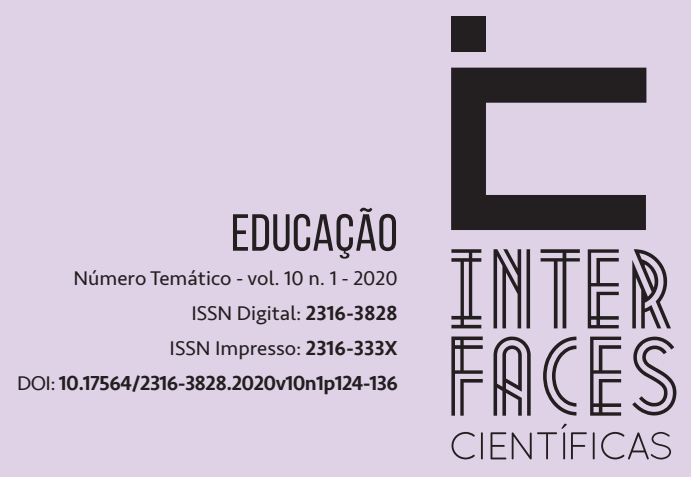

\section{A EDUCAÇ̃̃O ESPECIAL E A COVID-19: APRENDIZAGENS EM TEMPOS DE ISOLAMENTO SOCIAL}

\author{
SPECIAL EDUCATION AND COVID-19: \\ LEARNING IN TIMES OF SOCIAL ISOLATION
}

EDUCACIÓN ESPECIAL Y COVID-19: APRENDIZA IE EN TIEMPOS DE AISLAMIENTO SOCIAL
Karla Fernanda Wunder da Silva Katiuscha Lara Genro Bins ${ }^{2}$

Marlene Rozek ${ }^{3}$

\section{RESUMO}

A pandemia advinda da COVID-19 oportuniza que diversas lições sejam aprendidas e que novas configurações subjetivas sejam constituídas a respeito da Educação Especial e das pessoas com deficiência no enfrentamento do isolamento social imposto. As autoras elencam três lições que podem ser aprendidas com o momento atual vivenciado, apontando o quanto a pandemia pode ser excludente para aqueles que já se encontram socialmente excluídos, as pessoas com deficiência e suas famílias.

\section{PALAVRAS-CHAVE}

Educação Especial. COVID-19. Isolamento Social. 


\section{ABSTRACT}

The pandemic arising from COVID-19 makes it possible for several lessons to be learned and for new subjective configurations to be constituted regarding Special Education and people with disabilities in facing the imposed social isolation. The authors list three lessons that can be learned from the current experience, pointing out how much the pandemic can be exclusive for those who are already socially excluded, people with disabilities and their families.

\section{KEYWORDS}

Special Education. COVID-19. Social Isolation

\section{RESÚMEN}

La pandemia que surge de COVID-19 hace posible que se aprendan varias lecciones y que se constituyan nuevas configuraciones subjetivas con respecto a la educación especial y las personas con discapacidad para enfrentar el aislamiento social impuesto. Los autores enumeran tres lecciones que se pueden aprender de la experiencia actual, señalando cuanto puede ser la pandemia exclusiva para aquellos que ya están socialmente excluidos, las personas con discapacidad y sus familias.

\section{PALABRAS CLAVE}

Educación Especial, COVID-19, Aislamiento social

\section{INTRODUÇ̄̃̃O}

A claridade pandêmica e as aparições em que ela se materializa. 0 que ela nos permite ver e o modo como for interpretado e avaliado determinarão o futuro da civilização em que vivemos. Estas aparições, ao contrário de outras, são reais e vieram para ficar. A pandemia é uma alegoria. (SANTOS, 2020, p. 10).

0 presente texto é uma reflexão crítica e dialogada entre as autoras a partir do livro de Boaventura de Souza Santos (2020) A cruel pedagogia do vírus, no qual o autor aborda de forma lúcida e embasada diferentes lições que a sociedade pode aprender com a pandemia da COVID-19. Optamos usar da mesma lógica das lições possíveis de serem aprendidas com a COVID-19, enquanto sujeitos educadores que se constituem subjetivamente em relação dialógica com o mun- 
do e suas possibilidades de experiências, vivências e desafios, visto que aprendizagem e subjetividade estão presentes em diferentes espaços sociais de inserção do sujeito (MITJÁNS MARTÍNEZ et al., 2014, p. 5).

Não podemos deixar de destacar que toda a produção de conhecimento, neste caso, o impacto da COVID-19 na vida dos sujeitos público-alvo da Educação Especial é um processo permanente de nossa subjetividade, que de maneira contínua, provoca em nós, professoras/pesquisadoras reflexões e dúvidas constantes, já que é a expressão de nossas configurações subjetivas a respeito de nosso cotidiano em seus desdobramentos que vão gerar as construções intelectuais sobre o saber que nos propomos aqui a refletir e expor.

As reflexões partem de como percebemos e vislumbramos a Educação Especial e as lições da pandemia fundamentadas no texto de Santos (2020), partindo da perspectiva que a pandemia é algo concreto e tem impactos muito diferentes, fazendo padecer os grupos mais vulneráveis, do ponto de vista econômico-político e social. A entendemos sob o viés socioeducacional, dessa forma buscamos então refletir como podemos nos constituir e (re)construir nossas relações sociais, educacionais e afetivas, neste momento em que as certezas socialmente construídas parecem não fazer muito sentido.

Em situações excepcionais, como a da pandemia que acontece em função da COVID-19, podemos perceber indicadores e funcionamentos de uma sociedade que busca, mesmo em frente a iminência de muitas perdas humanas, a manutenção do status quo ou da emergência de novas aprendizagens que podem florescer em novos padrões de comportamentos sociais, alterando a normalidade vigente da sociedade atual capitalista em que vivemos (SANTOS, 2020).

A palavra pandemia vem do grego e significa: pan - tudo/todos e demos - povo, ou seja, é uma epidemia de uma certa doença infecciosa que acaba por se espalhar entre a população de um continente, uma região geográfica ou até mesmo de todo o planeta Terra (GREENBERG et al., 2005). Neste sentido, para nos precavermos do contágio, cuidarmos da nossa saúde a Organização Mundial da Saúde (OMS) orienta que seja feito o isolamento social. Para Santos (2020, p. 7),a tragédia é que neste caso a melhor maneira de sermos solidários uns com os outros, é isolarmo-nos uns dos outros e nem sequer nos tocarmos.

Compreendemos que a vida é uma rede de complexas e imbricadas relações e transformações, biológicas, cognitivas e sociais. A existência humana é compreendida a partir da coexistência com os outros, das trocas, dos desafios. A pandemia tem então nos ensinado o quanto é importante e valoroso acordar para mais um dia de vida, estabelecer trocas e vínculos sociais e afetivos e, no atual momento, a importância destes, mesmo que de forma virtual. 0 distanciamento, como afirma Santos (2020), nos torna solidários, o cuidar de si e ficar em casa torna-se o cuidar dos outros, o pensar coletivamente.

Porém, o autor afirma que qualquer tipo de quarentena é sempre discriminatória (SANTOS, 2020, p. 15), pois se torna essencialmente mais difícil para alguns grupos do que para outros. Isso acontece porque socialmente existem grupos que vivenciam em seu cotidiano uma vulnerabilidade que subsiste, muito antes desta pandemia que assolou o mundo e que acaba se agravando com este isolamento imposto pela COVID-19. Estes grupos representam o resultado social causado por uma exploração capitalista, que amplia e sustenta os preconceitos raciais, sexuais, entre outros. 
Sustenta-se no discurso de que vale mais para uma sociedade ter ao invés de ser, pelo discurso da produtividade para o mundo, da funcionalidade do ser humano. Entre esses grupos encontram-se as mulheres, trabalhadores autônomos e/ou informais, trabalhadores de rua, moradores de rua, de periferias da cidade, as favelas, refugiados ou imigrantes ainda sem condições legais de trabalho e moradia, idosos e, claro, as pessoas com deficiência (SANTOS, 2020).

0 vírus então acaba colocando em evidência e agravando as desigualdades sociais e educacionais, assim, ao pensar nas lições que o vírus pode nos ensinar, vislumbramos que existem oportunidades de mudanças no futuro.

Até o início da pandemia, quando ainda o vírus não nos afetava de maneira direta, eram apenas notícias na mídia, tínhamos a ilusão de achar que possuíamos o domínio total e a capacidade de manobrar o complexo mundo à nossa volta. 0 vírus está nos mostrando que precisamos nos reinventar, ou seja, significar o quanto as relações sociais, o aprender com o outro, o diálogo, o abraço, são fundamentais para nossa constituição enquanto sujeito. Necessitamos estar e ser com os outros para que nossa humanidade seja sempre reconstruída. Vamos aprendendo lições importantes com a propagação da nova doença e com a necessidade de recolhimento social. Precisamos o tempo todo refletir sobre nosso papel enquanto educadores neste país tão desigual, em que a educação é tão pouco valorizada e que, neste momento, mostra-se tão necessária.

Como educadoras e pesquisadoras da área da Educação Especial, destacamos algumas lições / aprendizagens que temos realizado frente ao contexto atual.

\section{LIÇÃO 1: Isolamento Social: experimentando o que as pessoas com deficiência vivem no cotidiano}

Nesta situação de isolamento social, em que por orientação dos governos estaduais há o impedimento de frequentar a escola por um tempo indeterminado, pois não há ainda certeza do retorno, a angústia é presente; momento em que a frequência aos diversos atendimentos que normalmente os sujeitos com deficiência necessitam em seu cotidiano como: acompanhamento psicológico, fonoaudiólogo, terapias ocupacionais, também não estão acontecendo, temos nos perguntado: como ficam os sujeitos com deficiência? Como estão sendo assistidos, eles e suas famílias, em suas demandas de apoio e escuta, de orientação e o principal, de acolhimento?

Santos afirma que: uma pandemia desta dimensão provoca justificadamente comoção mundial. Apesar de se justificar a dramatização, é bom ter sempre presente as sombras que a visibilidade vai criando" (SANTOS, 2020, p. 9). Por exemplo, ao refletirmos sobre isolamento e visibilidade social, o estar só, normalmente faz parte da vida das pessoas com deficiência e suas famílias. A segregação social ainda é muito presente no cotidiano destes indivíduos, pois uma parcela da sociedade ainda não aceita a pessoa com deficiência, seus direitos e não vislumbra suas potencialidades. Como indica Ferreira (2009, p. 116):

A consequente ignorância acerca de diversidade no âmbito das características das várias deficiências e da diversidade de habilidades / potencialidades de pessoas com deficiência, associadas à consolidação do modelo médico psicológico, (que explica a deficiência 
com base nas supostas limitações e incapacidade de aprender), acabou por criar e perpetuar uma cultura de desvalorização da pessoa com deficiência ao ponto de ser negado a essa população sua condição de cidadão / cidadã sujeito de direitos. 0 resultado dessa perversa concepção é a sólida exclusão social e educacional deste grupo social.

Ao conviver com famílias e alunos, ainda nos chegam relatos de que as crianças e jovens com deficiência não são convidadas para festas de aniversários pois podem atrapalhar e assustar outras pessoas; alguns profissionais da saúde ainda não conseguem lidar com maneirismos ou desorganizações psíquicas em consultas; professores acabam justificando o não aprender do aluno devido somente a sua deficiência. Lau Patrón nos mostra esse sentimento de exclusão em vários trechos de seu livro 71 leões como o que segue:

Era a primeira vez que me sentia humilhada pelo preconceito, pela falta de preparo, de empatia, de inclusão. [...] Tudo era difícil. Tenho centenas de experiências cruéis que vivenciei a partir do olhar e das palavras dos outros. Entendi naqueles dias que a sociedade vê a pessoa com deficiência como um problema não desejado, e se sente no direito de tratá-lo como tal. Nós somos inconvenientes. Lentos. Feios. Difíceis de tolerar. Qualquer atitude positiva é um mero favor. Assim como era um favor deixarem o João frequentar aquela escola. De todas as experiências que vivi, as mais difíceis foram no contato com outros pais. Estar em uma pracinha e ver os adultos afastarem seus filhos do João, como se ele tivesse algo contagioso, me feriu muito [...]. (PATRÓN, 2018, p. 218).

Todas estas situações elencadas, fazem com que as famílias em sua grande maioria, passem a buscar um isolamento social, pelo bem estar emocional ou com a intenção de proteger seus filhos. Este isolamento não é saudável, não é bom para as famílias e nem para as pessoas com deficiência. Mas ele acontece, de forma insistente, sustentado por preconceitos ainda vigentes neste século que apontam a desigualdade e a desvalorização entre as pessoas a partir de sua constituição física, cognitiva ou emocional.

Pensamos que, conceitualmente, no que tange aos direitos e acessos das pessoas com deficiência na sociedade e nas escolas, os avanços foram significativos. Porém, acreditamos que precisamos reconhecer este isolamento constante destes sujeitos e suas famílias. Precisamos incluir nos debates educacionais, políticos e socioculturais de maneira mais pontual este distanciamento social permanente vivenciado pela grande maioria das famílias e seus filhos com deficiência. Precisamos mediar os referenciais teóricos da inclusão com as necessidades e aspirações das pessoas com deficiência. Apontamos Rozek (2009, p. 16) que afirma:

Ao longo das últimas décadas, temos a temática da educação inclusiva inscrita em diferentes contextos e circunstâncias e a instituição escolar tem sido convocada a dar algum tipo de resposta. 0 atual momento histórico exige uma participação efetiva da escola e, para tanto, é preciso redimensionar o modo de pensar e fazer educação, tarefa complexa por natureza. 
Nesta perspectiva, propomos que se paute o quanto a deficiência é socialmente construída sob o viés do conceito do capacitismo, que acaba por influenciar a visão que toda a sociedade tem sobre os indivíduos. Tomamos o conceito de Capacitismo (PEREIRA, 2008) como a discriminação e o preconceito social contra as pessoas que apresentam alguma deficiência. Em sociedades capacitistas, como a nossa, é considerado normal as pessoas não terem nenhuma deficiência, sendo assim, a exceção é ter deficiência. Nesta perspectiva, a deficiência é vista como algo a ser superado ou corrigido.

Usa-se o conceito de Capacitismo para descrever as discriminações e opressões contra as pessoas com deficiência, que surgem da ideia preconceituosa de que elas são inferiores às pessoas sem deficiência (PEREIRA, 2008). Esse movimento do Capacitismo, que gera a exclusão social efetiva, é um conceito que a escola também precisa se preocupar nos tempos atuais. Santos (2020, p. 20) afirma que as pessoas com deficiência:

Têm sido vítimas de outra forma de dominação, além do capitalismo, do colonialismo e do patriarcado: o capacitismo. Trata-se da forma como a sociedade os discrimina, não thes reconhecendo as suas necessidades especiais, não thes facilitando acesso à mobilidade e às condições que lhes permitiriam desfrutar da sociedade como qualquer outra pessoa.

Todos nós vivenciamos agora este isolamento. Lógico, em propensões socialmente menos excludentes, mas conseguimos perceber nas horas que passam, enquanto não temos o acesso à escola, ao trabalho, aos espaços de lazer, a falta que sentimos do contato físico com as pessoas, a importância do pertencimento a um grupo social, do quanto manter-se ativo e circulando socialmente vai nos mantendo atentos às novas aprendizagens e novas experiências de vida. Ser social faz parte do ser humano. Isolar-se amplifica toda a dificuldade que possamos ter em estabelecer novos relacionamentos afetivos ou em manter as relações que já estavam estabelecidas. 0 isolamento acaba por ser mais cruel para determinadas classes sociais, já que muitas vezes as classes menos favorecidas não dispõem das tecnologias que podem aproximar as pessoas.

$\mathrm{O}$ isolamento social agora imposto pelo vírus faz com que possamos compreender o que vivenciam as pessoas com deficiência e suas famílias no seu cotidiano há vários anos. Quando a pandemia passar, talvez tenhamos uma sociedade mais acolhedora e empática com as diferenças humanas. Talvez, tenhamos uma sociedade que realmente entenda a importância da inclusão, e que ela não se configura um favor, mas um direito adquirido.

\section{LIÇÃO 2: 0 Vírus: a evidência das desigualdades sociais e a valorização dos vínculos afetivos para cons- tituição enquanto sujeitos das pessoas com deficiência ou alunos público alvo da Educação Especial}

As constatações, as vivências e as reflexões sobre a pandemia nos colocam face a face com nossas limitações, dificuldades e situações complexas, muitas vezes, recorrentes na vida das pessoas com deficiência.

$\mathrm{O}$ vírus tem se mostrado insidioso e imprevisível. Quando iniciamos o isolamento, não tínhamos a ideia de que levaria muito tempo e até agora não temos nenhuma previsão de retorno às atividades cotidianas, estamos vivendo mês a mês. $O$ fato de ser algo que não vivenciamos, nos faz ficar sem pa- 
râmetros, o que nos provoca sentimentos de angústia, medo, insegurança e a privação de liberdade. A quarentena torna mais visíveis as injustiças sociais, a exclusão, a fragilidade humana e o sofrimento dos setores mais vulneráveis da sociedade.

Pontuamos então que mediante as situações que o vírus tem imposto a nós, precisamos fortalecer as relações humanas com o objetivo de cuidar da saúde mental, bem como buscar diminuir as desigualdades sociais.

Cuidar da saúde mental, a nossa e a dos outros, implica em utilizar, quando necessário, dos recursos disponibilizados por diversos profissionais para a escuta do outro, do acolhimento emocional para as pessoas que não estão conseguindo enfrentar o isolamento sem sofrer. Bem como, mais do que nunca, buscar diminuir as desigualdades sociais, cobrando do Estado a implementação de políticas públicas sociais e econômicas que ofereçam alguma opção para as famílias mais carentes e incentivar a mobilização social de cooperação com os mais vulneráveis, contando com a arrecadação e distribuição de gêneros alimentícios, roupas, materiais de higiene, entre outros. A ideia de que o mundo todo atravessa as mesmas dificuldades e que de uma forma ou de outra podemos ser ponte de ajuda para alguém, acaba por unir às pessoas por sentimento de solidariedade e empatia.

Percebemos que existe uma sensação de coletividade em relação a pandemia, ou seja, estamos todos vivenciando, a mesma situação de excepcionalidade. Neste momento em que lutamos contra algo que é invisível aos nossos olhos, precisamos apoiar uns aos outros, cada vez mais. A situação da pandemia coloca todos na mesma situação, pois o vírus parece que não é preconceituoso, atinge a todos, porém ele não é tão democrático, a letalidade atinge os idosos, indivíduos com problemas associados e os socialmente vulneráveis.

Há muito tempo, o ser humano busca encontrar um significado, um sentido para a existência, por meio de explicações religiosas, científicas ou filosóficas. Temos gerado ao longo dos anos várias formas de pensar, de viver, num movimento contínuo e dinâmico. Sempre há muitas formas e vários sentidos para interpretar e compreender o mundo, mas o momento atual aponta para a urgência do fortalecimento das relações humanas.

Depreendemos então a necessidade de manter os vínculos por meio da troca de olhares, o afeto de estar presente mesmo longe. A presença física e mesmo a virtual é importante e faz diferença na vida de todos. Não é o ideal, sabemos disto, mas é o que o momento nos impõe e para os alunos com deficiência e suas famílias a valorização dos afetos, o estar presente é algo fundamental neste momento, para que possam enfrentar os desamparos afetivos e sociais que vivenciam. Sobre isso, concordamos com Walz (2005, p. 9) ao afirmar que:

Ao conversarmos com alguém, é valioso quando alguma lembrança, uma memória agradável ou uma palavra deixam uma marca, um rastro. Melhor ainda quando estamos com alguém em cuja presença nos sentimos à vontade e com um mínimo de certeza de que podemos falar e que desse interlocutor teremos alguma palavra que não nos deixará no vazio da intensidade. Certas palavras, gestos e acolhimentos ficam para sempre guardados; quando precisamos recorrer a alguma ajuda, a algum consolo, essas situações ou 
momentos retornam à nossa memória com força tranquilizadora. A isso chamarei de cuidado ou construção de pontes na vida mental, alicerces importantes para que se possa enfrentar o desamparo e os medos da vida.

O futuro é incerto, não sabemos como será o mundo após a pandemia. Cabe aqui perceber que se o fortalecimento das relações persistirem e conceitos como colaboração, cuidado com o outro, escuta, solidariedade igualdade social e respeito às diferenças se tornarem cotidianos, talvez, no final desta pandemia, o mundo se torne mais sensível, mais acolhedor, mais pautado sobre o conceito de ser do que de ter. Concordamos também com Santos (2020, p. 32) quando ele propõe que é preciso:

[...] uma viragem epistemológica, cultural e ideológica que sustente as soluções políticas, económicas e sociais que garantam a continuidade da vida humana digna no planeta. Essa viragem tem múltiplas implicações. A primeira consiste em criar um novo senso comum, a ideia simples e evidente de que sobretudo nos últimos quarenta anos vivemos em quarentena, na quarentena política, cultural e ideológica de um capitalismo fechado sobre si próprio e a das discriminações raciais e sexuais sem as quais ele não pode subsistir. A quarentena provocada pela pandemia é afinal uma quarentena dentro de outra quarentena. Superaremos a quarentena do capitalismo quando formos capazes de imaginar o planeta como a nossa casa comum e a Natureza como a nossa mãe originária a quem devemos amor e respeito. Ela não nos pertence. Nós é que lhe pertencemos. Quando superarmos esta quarentena, estaremos mais livres das quarentenas provocadas por pandemias.

O vírus então pode nos ensinar lições importantes sobre os valores humanos, sobre buscar alternativas que possam proteger e defender a vida acima dos interesses da economia, fortalecendo e valorizando as relações sociais para nossa constituição subjetiva. A valorização, a manutenção dos vínculos e os cuidados com a saúde mental são fundamentais neste momento de pandemia, para as pessoas com deficiência ou para os alunos público alvo da Educação Especial.

\section{LIÇÃO 3: A Educação Especial: aprendizagens que precisamos construir em tempos de Pandemia}

E as zonas de invisibilidade poderão multiplicar-se em muitas outras regiões do mundo, e talvez mesmo aqui, bem perto de cada um de nós. Talvez baste abrir a janela. (SANTOS, 2020, p. 9).

Nossa intenção com esta lição é poder realizar uma crítica socioeducacional do momento em que vivemos para que possamos refletir, na busca de construir novas aprendizagens. As pessoas com deficiência padecem de uma vulnerabilidade que preexiste à quarentena. Em situações de crise como a que vivenciamos, ficam claras as condições precárias de políticas públicas de saúde e assistência social, de privação e exclusão que vivem as pessoas com deficiências e suas famílias, o que reforça uma condição de ineficiência e de exclusão que é histórica. Santos (2020, p. 20) afirma que em relação a estes sujeitos: 
De algum modo, as limitações que a sociedade thes impõe fazem com que se sintam a viver em quarentena permanente. Como viverão a nova quarentena, sobretudo quando dependem de quem tem de violar a quarentena para lhes prestar alguma ajuda? Como já há muito se habituaram a viver em condições de algum confinamento, sentir-se-ão agora mais livres que os «não-deficientes» ou mais iguais a eles? Verão tristemente na nova quarentena alguma justiça social?

O público alvo da Educação Especial está, novamente, invisível nas políticas públicas, decretos e decisões criadas pela Pandemia, generalizam-se as condições humanas, deixando as pessoas com deficiência à margem das decisões e processos, sem que seus direitos, suas necessidades e particularidades sejam reconhecidas e contempladas. Contudo, o discurso político-educacional considera que todos se encontram nas mesmas condições. A realidade se impõe e nos mostra que ainda as pessoas com deficiência não se encontram em situação de equidade de acesso às diferentes possibilidades tecnológicas, sociais e culturais existentes.

Acreditamos, então, que precisamos de uma análise profunda sobre estas condições de existência e ponderar de que maneira vislumbramos a Educação Inclusiva neste momento em que as relações humanas acontecem de maneira virtual, direitos não são contemplados e a invisibilidade é reforçada, mais uma vez. É um momento que precisamos (re)pensar e (re)estruturar a Educação Inclusiva no mesmo instante em que as demandas se colocam presentes. Situações que exigem a busca de um novo modo de ser e de se fazer Educação, no sentido de que precisamos atuar, levando em conta valores éticos e coletivos, superando as imensas desigualdades sociais a que estamos todos submetidos, mas, em especial, as pessoas com deficiência e suas dificuldades cotidianas de acesso e afirmação da cidadania. Para Freire (1982, p. 39):

É algo importante perceber que a realidade social é transformável; que feita pelos homens, pode ser mudada; não é algo intocável, um fado, uma sina, diante de que só houvesse um caminho: a acomodação a ela. É algo importante que a percepção ingênua da realidade vá cedendo lugar a um a percepção que é capaz de perceber-se; que o fatalismo vá sendo substituído por uma crítica esperança que pode mover os indivíduos a uma cada vez mais concreta ação em favor da mudança radical da sociedade.

Precisamos nos reinventar para proporcionar o acesso e continuar mantendo os vínculos entre professores e alunos, nem que seja por alguns breves instantes pela forma virtual, respeitando a suportabilidade dos alunos, bem como, em alguns momentos, auxiliando as famílias em suas demandas, sendo realmente pontes de sustentação emocional para alunos e famílias.

A modalidade de Educação à distância, on-line é posta, neste momento, como uma alternativa de atendimento aos alunos em diversos níveis e modalidades do sistema educacional brasileiro. Enquanto profissionais da Educação Especial, temos a clareza que as aulas à distância ou aulas on-line não substituem as aulas presenciais, sabemos a importância da presença física para os alunos com 
deficiência, acreditamos que [...] são as relações humanas que nos permitem aprender, são os afetos que dão significado às aprendizagens (ZILIO, 2005, p. 21).

Porém, entendemos que, não tendo condições da presença física, outras possibilidades são necessárias para manter os vínculos. Esta é uma aprendizagem que a pandemia nos trouxe. E aí as tecnologias por videochamadas, encontros coletivos por meio de diferentes plataformas, ligações telefônicas mais longas que substituem as mensagens rápidas se tornam alternativas para manter a proximidade com o outro.

Em relação à educação à distância ou on-line, outro aspecto a ser pensado é que na educação pública encontramos dificuldades estruturais e financeiras, ou seja, a maioria das casas dos alunos da escola pública fica na periferia, onde não há aparelhos ou internet que possam dar conta das demandas de um ensino nestes modelos propostos.

Assim, sendo a condição que se impõe no momento, precisamos adaptá-la da melhor forma possível para os alunos com deficiência. 0 processo da apropriação da aprendizagem é subjetivo. Os sujeitos vão responder de maneira diferenciada àquilo que foi ensinado, a partir de seus objetivos e desejos. Certamente, o contato virtual não é ideal para a aprendizagem dos sujeitos com deficiência, como entendemos não ser ideal para todos os alunos. Algumas aprendizagens podem não acontecer, mas não significa que outras não possam emergir.

Talvez mais do que aprendizagens ditas acadêmicas, conteudistas, os alunos neste momento precisam aprender o valor da vida, a importância do autocuidado, a importância de poderem falar de seus sentimentos, medos, angústias. A aprendizagem formal pode ser recuperada, a hora agora é cuidar do ser humano. Acreditamos que a educação também aqui tem papel importante. Mostrar aos alunos e famílias a falta que faz estarmos todos juntos, podendo trocar e dialogar e que em algum momento estaremos fisicamente juntos de novo.

Todo o ser humano é único e, sendo assim, sua aprendizagem e seu desenvolvimento também o são. As interações socioafetivas que estabelecemos com nossos alunos com deficiência são imprescindíveis para o seu desenvolvimento e, pontualmente devem ser feitas de maneira virtual para manter de alguma forma o engajamento dos alunos nas relações afetivas e de aprendizagem que se estabeleceram durante o convívio presencial. E mesmo com todo o empenho e dedicação é certo, inevitavelmente, que alguns ainda ficarão à margem, pois a sociedade capitalista em que vivemos não oferta para todos as mesmas condições financeiras, o que inviabiliza o acesso às tecnologias mais modernas, tão necessárias neste cotidiano.

Acreditamos que vários são os desafios no atual momento de distanciamento social, mas entendemos que podem ser superáveis, é uma questão de querer pensar, construir, colocar em prática situações que promovam trocas, presença e convivência virtuais. Buscar metodologias interativas voltadas para as necessidades de cada aluno é um exercício neste momento.

Finalizamos pontuando que neste tempo em que vivemos, de isolamento, somos impulsionados enquanto sociedade a buscar e implementar alternativas que possam fortalecer a saúde e a educação em todo o país. Aconteceu uma união da classe médica e dos profissionais de saúde, atendendo ao chamado para atuarem na linha de frente desta pandemia. 
Houve troca de descobertas científicas, buscando soluções para interromper contágio e ofertar melhores condições aos doentes. Construção de hospitais de campanha, em parcerias com empresas privadas para acolher os doentes e minimizar a sobrecarga dos hospitais. A educação precisou se adaptar ao novo momento, assumindo novas propostas como aulas on-line, Educação a Distância, utilizando ferramentas que antes eram apenas sociais (facebook, watts, instagran, entre outros) para ofertar o acesso dos alunos ao conhecimento. Santos (2004, p. 2) já afirmava em outros tempos que é necessário a:

União de cidadãos trabalhando em ações voluntárias, para conversar, discutir, criar soluções. É essa concepção de sociedade civil, baseada na solidariedade, voluntariado e reciprocidade, que nos interessa hoje. Vivemos em um mundo onde queremos ser simultaneamente iguais e diferentes. Pensamos uma cidadania planetária que respeite as diferentes culturas. Não queremos um falso universalismo que destrói todas as diferenças e que impôs a cultura branca, masculina e ocidental como um padrão universal.

\section{CONSIDERAÇÕES FINAIS}

Neste cenário marcado pela pandemia temos duas opções, enquanto vivemos todas as experiências que o cotidiano nos impõe, ou seguimos com nossas vidas, só acreditando que tudo vai passar e vamos retomar nossas rotinas da mesma forma, na busca constante de ser mais e fazer mais, ou aproveitamos esta parada para refletir e ao fazê-lo, nos tornamos mais empáticos e solidários, mais acolhedores e menos preconceituosos com toda e qualquer diferença, entendendo-as como valorosas na constituição humana.

Cremos que só na segunda opção sairemos vitoriosos deste processo, de outra forma, seremos pessoas que aprenderão a viver mais separadas do que a sociedade já vivia. Temos a certeza de que a normalidade como a identificávamos não poderá mais existir, mas um novo normal, que sustente o afastamento, o isolamento ou o individualismo como forma de relação também não é aceitável.

Entendemos que, considerando as dimensões epistemológica política, sociocultural e histórica vivenciadas pelas pessoas com deficiências, é preciso buscar alternativas para que as condições precárias de políticas públicas de saúde e assistência social, de privação e exclusão que elas e suas famílias vivem, possam mudar.

Ainda há muitas questões a serem discutidas, pesquisadas e vivenciadas acerca deste momento e suas consequências para a Educação Especial na perspectiva da educação remota para os alunos com deficiência e de uma cultura de acolhimento destes sujeitos e suas famílias. Nosso objetivo com o presente artigo é que ele possa provocar divergências e convergências sobre a inclusão escolar e social das pessoas com deficiência frente às demandas impostas por uma pandemia que exigem da sociedade e das políticas públicas respostas efetivas e assertivas. 


\section{REFERÊNCIAS}

FERREIRA, W. B. EJA e Deficiência: estudo da oferta da modalidade EJA para estudantes com deficiência. In: PAIVA, J.; BARBOSA, M.J. (org.). Educação de Jovens e Adultos: o que dizem as pesquisas. Recife: J. Luiz Vasconcelos, 2009. 128p.

FREIRE. Paulo. Ação Cultural para a liberdade. Rio de Janeiro: Paz e Terra, 1982. MITJÁNS MARTÍNEZ, Albertina et al. Subjetividade Contemporânea. Discussões epistemológicas e metodológicas. Campinas: São Paulo. Editora Alínea, 2014.

GREENBERG, Raymond S. et al. Epidemiologia Clínica 3. ed. Porto Alegre: Artmed, 2005.

PATRÓN, Lau. 71 Leões. Uma história sobre afeto, dor e renascimento. Caxias do Sul, RS: Belas Letras, 2018.

PEREIRA, A. M. B. A. Viagem ao Interior da Sombra: deficiência, doenças crônicas e invisibilidade numa sociedade capacitista. 2008. 257f. Dissertação (Mestrado) - Curso de Centro de Estudos Sociais, Faculdade de Economia, Universidade de Coimbra, Coimbra, 2008. Disponível em: https:// estudogeral.sib.uc.pt/handle/10316/8517. Acesso em: 7 abr. 2020.

ROZEK. M. A Educação especial e a educação inclusiva: compreensões necessárias. Revista Reflexão \& Ação, Santa Cruz do Sul, v. 17, n. 1. p. 164-183, 2009. [versão online: p. 1-19]. Disponível em: http://online.unisc.br/seer/index.php/reflex/article/view/918/665. Acesso em: 20 out. 2012.

SANTOS, Boaventura de Souza. A cruel pedagogia do vírus. Coimbra: Edições Almeida, S.A, 2020.

SANTOS, Boaventura de Sousa. Conhecimento prudente para uma vida decente: um discurso sobre as ciências revisitado. São Paulo: Cortez.2004

WALZ, Julio. Aprendendo a lidar com os medos. São Leopoldo-RS: Sinodal, 2004.

ZILIO. Marisa Potiens. O Brasil e o problema da inclusão. In: LEBEDEFF, Tatiana Bolivar; PEREIRA, Isabella Lima e Silva Pereira. Educação Especial: olhares interdisciplinares. Passo Fundo: UPF, 2005. 
1 Mestra em Educação pela Universidade Federal do Rio Grande do Sul; Doutoranda em Educação pela Pontifícia Universidade Católica do Rio Grande do Sul; Psicopedagoga e Pedagoga Especial; Integrante do Núcleo de Pesquisas sobre Aprendizagem e Processos Inclusivos (NEPAPI) - PUCRS; Experiência na área de Educação, atuando principalmente nos seguintes temas: Transtorno do Espectro Autista, Deficiência Intelectual, Educação Inclusiva, Educação Especial, Formação de professores, Gestão Educacional, Processos Inclusivos, Adequações Curriculares, Subjetividade e Psicopedagogia.

E-mail: karla.silva@acad.pucrs.br

2 Doutora em Educação pela Pontifícia Universidade Católica do Rio Grande do Sul; Mestra em Educação pela Pontifícia Universidade Católica do Rio Grande do Sul; Especialista em Alfabetização e Pedagoga Especial; Integrante do Núcleo de Pesquisas sobre Aprendizagem e Processos Inclusivos (NEPAPI) - PUCRS; Experiência na área de Educação, atuando principalmente nos seguintes temas: Educação Especial, Educação Inclusiva, Gestão dos processos inclusivos, Deficiência Intelectual, Transtorno do Espectro Autista, Formação de professores, Alfabetização, Aprendizagem e Educação de Jovens e Adultos.

E-mail: katigbins@gmail.com

3 Doutora em Educação pela Universidade Federal do Rio Grande do Sul - UFRS; Mestra em Educação pela Pontifícia Universidade Católica do Rio Grande do Sul - PUCRS; Psicopedagoga e Pedagoga Especial; Integrante do comitê científico consultivo - Universidad de Zaragoza e professora do Curso de Pedagogia e do Programa de Pós-Graduação em Educação da Escola de Humanidades - PUCRS; Coordenadora do Núcleo de Estudos e Pesquisas sobre Aprendizagem e Processos Inclusivos (NEPAPI) -a PUCRS; Experiência na área de Educação, atuando principalmente nos seguintes temas: Psicopedagogia, Subjetividade, Educação Inclusiva, Educação Especial, Formação de professores e Intervenção precoce na infância.

E-mail: marlene.rozek@pucrs.br

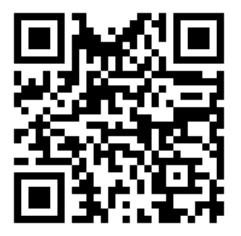

A autenticidade desse artigo pode ser conferida no site https://periodicos. set.edu.br

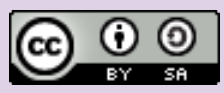

Este artigo é licenciado na modalidade acesso abertosob a Atribuição-Compartilhalgual CC BY-SA 